\title{
Thyroid hormone receptor $\beta 1$ suppresses proliferation and migration by inhibiting PI3K/Akt signaling in human colorectal cancer cells
}

\author{
LEI ZHU $^{1 *}$, GUANGANG TIAN ${ }^{1 *}$, QIN YANG ${ }^{1}$, GEJING DE ${ }^{2}$, ZHIGANG ZHANG ${ }^{1}$, \\ YAHUI WANG ${ }^{1}$, HUIZHEN NIE ${ }^{1}$, YANLI ZHANG ${ }^{1}$, XIAOMEI YANG ${ }^{1}$ and $\mathrm{JUN} \mathrm{LI}^{1}$ \\ ${ }^{1}$ State Key Laboratory of Oncogenes and Related Genes, Shanghai Cancer Institute, Renji Hospital, \\ School of Medicine, Shanghai Jiao Tong University, Shanghai 200240; ${ }^{2}$ Institute of Chinese Materia Medica, \\ China Academy of Chinese Medical Sciences, Beijing 100050, P.R. China
}

Received February 19, 2016; Accepted April 18, 2016

DOI: $10.3892 /$ or.2016.4931

\begin{abstract}
Thyroid hormone receptor $\beta 1$ (TR $\beta 1$ ) is a ligand-dependent transcription factor that belongs to the superfamily of nuclear receptors. TR $\beta 1$ has been found to act as a tumor suppressor in many solid tumors including breast cancer and hepatocellular carcinoma, but its role in the progression of human colorectal cancer (CRC) remains unclear. In this study, microarray data analysis revealed that TR $\beta 1$ mRNA was downregulated in CRC tumors compared with that in the normal counterparts in both The Cancer Genome Atlas (TCGA) and Gene Expression Omnibus (GEO) datasets. Using a CRC tissue microarray (TMA), we confirmed that the expression of TR $\beta 1$ was decreased in human CRC tumor tissues in contrast to normal colorectal mucosal tissues. Notably, the TR $\beta 1$ expression was strongly correlated with tumor size $(\mathrm{p}=0.045)$. Furthermore, we found that CRC cell proliferation and migration were significantly inhibited by TR $\beta 1$ overexpression in vitro. Mechanistic studies indicated that activated phosphorylated Akt was clearly suppressed by TR $\beta 1$ in the CRC tissues and cells. In conclusion, this study provides evidence that TR $\beta 1$ plays a critical role in the progression of CRC via the PI3K/Akt pathway, and the TR $\beta 1$ gene may represent a novel target for CRC therapeutics.
\end{abstract}

\section{Introduction}

Colorectal cancer (CRC) is the third most common cancer in males and the second in females; it also remains the third

Correspondence to: Dr Jun Li or Dr Xiaomei Yang, State Key Laboratory of Oncogenes and Related Genes, Shanghai Cancer Institute, Renji Hospital, School of Medicine, Shanghai Jiao Tong University, Room 419, Wenxuan Building of Medicine, 800 Dongchuan Road, Shanghai 200240, P.R. China

E-mail: junli@shsci.org

E-mail: xmyang@shsci.org

${ }^{*}$ Contributed equally

Key words: thyroid hormone receptor $\beta 1$, colorectal cancer, proliferation, migration, phospho-Akt leading cause of cancer-related deaths (1). Innovative therapeutic strategies have greatly improved the long-term survival of CRC patients over the past decade; however, a significant proportion of patients suffer from drug resistance, relapse and poor outcomes $(2,3)$. The development of CRC is a complex process involving a series of genetic and epigenetic alterations (4). Thus, understanding the molecular mechanisms of CRC carcinogenesis and progression are extremely crucial to improve CRC diagnosis and treatment.

Thyroid hormones [such as triiodothyroine $\left(\mathrm{T}_{3}\right)$ ] regulate the growth, development and differentiation in vertebrates (5). $\mathrm{T}_{3}$ binds to specific high affinity receptors [thyroid receptors (TRs)] which belong to the superfamily of nuclear receptors (6). They function as ligand-modulated transcription factors by binding to thyroid hormone response elements (TREs) located in the promoter regions of target genes (7). Two human TR genes, TR $\alpha$ and TR $\beta$, respectively, are located on human chromosomes 17 and 3. By alternative splicing and different promoter usage, these two genes yield at least four proteins: thyroid hormone receptor $\alpha 1$ (TR $\alpha 1)$, TR $\alpha 2$, thyroid hormone receptor $\beta 1$ (TR $\beta 1$ ), and TR $\beta 2$ (8). Most tissues of the human body express TRs, but there is differential expression of the TR isoforms. TR $\alpha 1$ predominates in skeletal muscle and brown fat, TR $\alpha 2$ in brain, TR $\beta 1$ in brain, liver and kidney, and TR $\beta 2$ in the central nervous system and developing retina (9-11).

Aberrant expression or mutation of TRs are common events in human cancer (12). Somatic mutation of TRs have been found in human hepatocellular carcinoma (13), renal clear cell carcinoma $(14,15)$, breast cancer $(16)$, pituitary tumors $(17,18)$ and thyroid cancer (19). Moreover, an increasing number of studies indicate that TRs are potent suppressors of tumorigenesis, invasiveness, and metastasis (20). Mice devoid of functional TRs $\left(\mathrm{TR} \alpha 1^{--}, \mathrm{TR} \beta 1^{--}\right.$) spontaneously develop follicular thyroid cancer and metastasis to the lung (21). In hepatocarcinoma cells transfected with TR, $\mathrm{T}_{3}$ was found to downregulate expression of pituitary tumor-transforming gene 1 (PTTG1) and inhibit cell growth (22). Martínez-Iglesias et al indentified that expression of TR $\beta 1$ in hepatocarcinoma and breast cancer cells reduced tumor growth and caused partial 
mesenchymal-to-epithelial cell transition (20). These findings suggest that TRs may act as tumor suppressors and constitute novel therapeutic targets in cancer.

In this study, we report that TR $\beta 1$ expression was decreased in human $\mathrm{CRC}$ tissues compared to that in normal controls. In two CRC cell lines overexpressing TR $\beta 1$, the cell proliferation and migration was suppressed. The PI3K/Akt signaling pathway plays an important role in tumor progression. It has been reported that Akt is over-activated in thyroid cancer in humans and in mice carrying mutated $\operatorname{TR} \beta$ genes $(23,24)$. Here, we identified that PI3K/Akt signaling was inactivated by TR $\beta 1$ expression in CRC tissues and cells.

\section{Materials and methods}

Clinical samples. A total of $222 \mathrm{CRC}$ tissue sections and adjacent normal colorectal mucosal tissues were collected from January 2008 to December 2010 at Renji Hospital, School of Medicine, Shanghai Jiao Tong University. All of the samples were formalin-fixed and paraffin-embedded. Important clinical data, such as tumor size, lymphatic metastasis, histological grade were collected from the medical records of 100 patients. In addition, 29 pairs of fresh CRC and adjacent specimens were available and snap-frozen in liquid nitrogen immediately after surgery and stored at $-80^{\circ} \mathrm{C}$ until use. All of the human materials were obtained with informed approval of the World Health Organization Collaborating Center for Research in Human Production (authorized by the Shanghai Municipal Government).

Cell culture. Two human CRC cell lines HCT116 (ATCC CCL-247) and SW620 (ATCC CCL-228) were obtained from the Shanghai Institute of Biochemistry and Cell Biology, Chinese Academy of Science (Shanghai, China), and separately cultured in RPMI-1640 medium and Dulbecco's modified Eagle's medium (DMEM) (Gibco, Carlsbad, CA, USA) supplemented with $10 \%(\mathrm{v} / \mathrm{v})$ fetal bovine serum (FBS) and $1 \%$ antibiotics (both from Gibco, Grand Island, NY, USA) at $37^{\circ} \mathrm{C}$ in a humidified incubator under $5 \% \mathrm{CO}_{2}$ condition.

Tissue microarray (TMA) and immunohistochemistry (IHC) staining. TMA was constructed by Suzhou Xinxin Biotechnology Co., Ltd. (Suzhou, China). Cores with a 2-mm diameter were collected from individual paraffin-embedded sections and arranged in the recipient paraffin blocks. Then, $5-\mu \mathrm{m}$ thick sections were placed on superfrost charged glass microscope slides.

Prepared slides were deparaffinized in xylene, and rehydrated in a series of graded ethanol. The antigens were retrieved in $0.01 \mathrm{M}$ sodium citrate buffer $(\mathrm{pH}$ 6.0) using a microwave oven, and $3 \%$ hydrogen peroxide was used to block endogenous peroxidase activity. After washing for $60 \mathrm{~min}$ in PBS with $10 \%$ BSA to prevent non-specific binding, the tissue slides were incubated with the primary antibody for TR $\beta 1$ (Clone J51, 1:50 dilution; Santa Cruz Biotechnology, Inc., USA) or pAkt (Ser473) (\#2118-1, 1:50 dilution; Abcam, USA) overnight at $4^{\circ} \mathrm{C}$. On the next day, the tissues were incubated with species-specific secondary antibodies $(1: 1,000$; Abcam) for $60 \mathrm{~min}$ at room temperature. Immunostaining was carried out using a DAB substrate kit (Thermo Fisher
Scientific, USA), followed by immersing into hematoxylin for nuclear counterstaining. A staining index was obtained as the intensity of positive staining (negative, 0; weak, 1; moderate, 2; or strong, 3 scores) and the proportion of immunopositive cells of interest was scored $(<25 \%, 1 ; 25-50 \%, 2 ;>50-75 \%, 3$; $\geq 75 \%$, 4). All scores were subdivided according to the median values of the study cohort into two categories: low expression ( $<$ median) and high expression ( $\geq$ median).

Quantitative real-time $P C R$. Total RNA from the human tissues or CRC cells was extracted using TRIzol reagent (Invitrogen, Carlsbad, CA, USA), and reversely transcribed through PrimeScript RT-PCR (Takara Bio, Inc., Shiga, Japan) according to the protocol. Real-time PCR analyses were performed with SYBR Premix Ex Taq (Takara Bio, Inc.) on a 7500 Real-Time PCR System (Applied Biosystems, Foster City, CA, USA) at the recommended thermal cycling settings: one initial cycle at $95^{\circ} \mathrm{C}$ for $30 \mathrm{sec}$ followed by 40 cycles of $5 \mathrm{sec}$ at $95^{\circ} \mathrm{C}$ and $31 \mathrm{sec}$ at $60^{\circ} \mathrm{C}$. The primers were as follows: human TR $\beta 1$ forward, 5'-TTACAGCCTGGGACAAACCG-3' and reverse, 5'-GCGACATTCCTGGCACTGAT-3'; human $\beta$-actin forward, 5'-AGTTGCGTTACACCCTTTCTTG-3' and reverse, 5'-CACCTTCACCGTTCCAGTTTT-3'. The relative expression of TR $\beta 1$ was calculated and normalized using the $2^{-\Delta \Delta \mathrm{Ct}}$ method relative to $\beta$-actin. Independent experiments were conducted in triplicate.

Lentiviral overexpression. The lentiviral expression system was obtained from System Biosciences (SBI; Mountain View, CA, USA). The cDNA encoding human TR $\beta 1$ was amplified and cloned into pCDH-CMV-MCS-EF1-Puro, and then the expression vector was co-transfected with packaging vectors psPAX and pMD2.G at a ratio of 3:2:1 into 293T cells using X-tremeGENE HP (Roche Diagnostics, GmbH, Mannheim, Germany). Lentiviruses were harvested at 48 and $72 \mathrm{~h}$ after transfection, and virus titers were determined. Target cells $\left(1 \times 10^{5}\right)$, including HCT116 and SW620 cells, were infected with $1 \times 10^{6}$ recombinant lentivirus-transducing units in the presence of $6 \mu \mathrm{g} / \mathrm{ml}$ polybrene (Sigma-Aldrich, St. Louis, MO, USA).

Dual-Luciferase reporter assay. TRE-activated firefly luciferase reporter vector (TRE-luc) was a kind gift from Dr Hao Ying at the Institute for Nutritional Sciences (SIBS), Chinese Academy of Sciences. The Renilla luciferase vector (pRL-TK) (Promega, Madison, WI, USA), driven by an HSV-TK promoter, was used as an internal control. HCT116 or SW620 cells were seeded in 96-well plates and co-transfected with TRE-luc $(0.1 \mu \mathrm{g} /$ well $)$ and Renilla control plasmids $(0.01 \mu \mathrm{g} /$ well) following the manufacturer's instructions. After $48 \mathrm{~h}$, the CRC cells were treated with $10 \mathrm{nM}$ 3,3',5-triiodo-L-thyronine $\left(\mathrm{T}_{3}\right)$ (Sigma-Aldrich) with $\mathrm{dH}_{2} \mathrm{O}$ as a control, and incubated for further $24 \mathrm{~h}$. Luciferase activities were measured on a luminometer using the Dual-Luciferase reporter assay system (Promega) according to the manufacturer's instructions.

Cell viability and colony formation assay. Cells were seeded into a 96-well plate at 2,000 cells/well with $100 \mu \mathrm{l}$ complete medium and cultured at $37^{\circ} \mathrm{C}$. A total of $10 \mu \mathrm{l}$ Cell Counting 
A

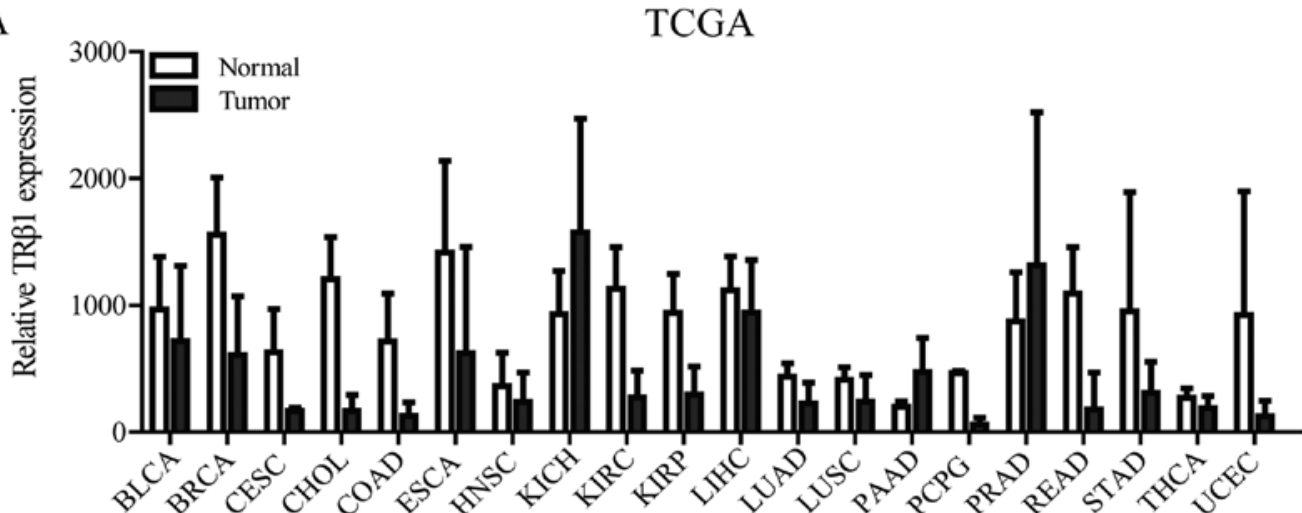

B
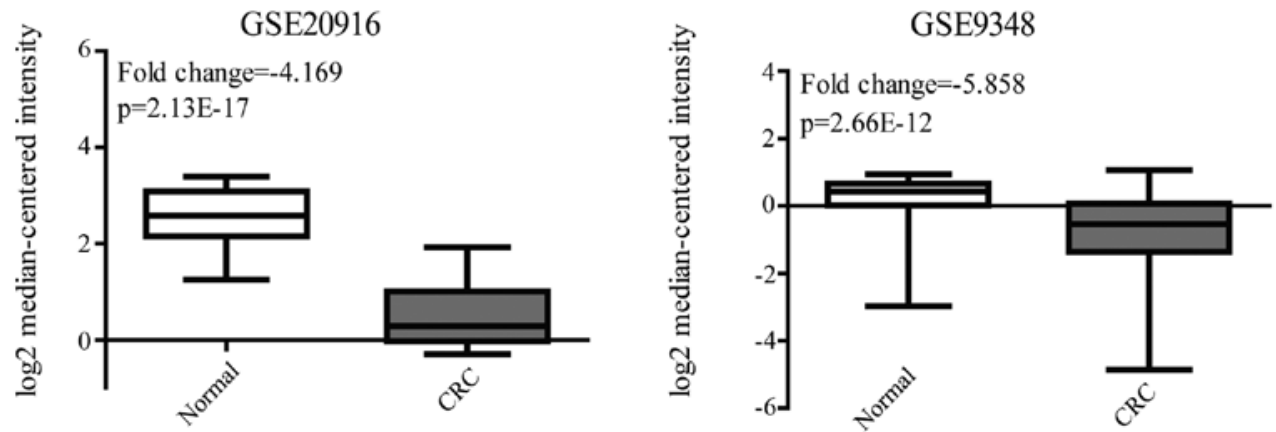

Figure 1. TR $\beta 1$ expression in TCGA and GEO datasets. (A) TR $\beta 1$ mRNA expression in paired tumor vs. normal tissues from the TCGA data. (B) TR $\beta 1$ mRNA expression in CRC tumor and normal mucosal tissues obtained from GSE20916 and GSE9348. TR $\beta 1$, thyroid hormone receptor $\beta 1$; TCGA, The Cancer Genome Atlas; GEO, Gene Expression Omnibus; BLCA, bladder urothelial carcinoma; BRCA, breast invasive carcinoma; CESC, cervical squamous cell carcinoma and endocervical adenocarcinoma; CHOL, cholangiocarcinoma; COAD, colon adenocarcinoma; ESCA, esophageal carcinoma; HNSC, head and neck squamous cell carcinoma; KICH, kidney chromophobe; KIRC, kidney renal clear cell carcinoma; KIRP, kidney renal papillary cell carcinoma; LIHC, liver hepatocellular carcinoma; LUAD, lung adenocarcinoma; LUSC, lung squamous cell carcinoma; PAAD, pancreatic adenocarcinoma; PCPG, pheochromocytoma and paraganglioma; PRAD, prostate adenocarcinoma; READ, rectum adenocarcinoma; STAD, stomach adenocarcinoma; THCA, thyroid carcinoma; UCEC, uterine corpus endometrial carcinoma; CRC, colorectal cancer.

Kit-8 (CCK-8) (WST-8; Dojindo Molecular Technologies, Inc., Kumamoto, Japan) solution was added to each well after 24, 48, 72, 96 and $120 \mathrm{~h}$, respectively. After $1 \mathrm{~h}$ of incubation, WST-8 was metabolized to produce a colorimetric dye that is detected at OD450 $\mathrm{nm}$ by using a PowerWave XS microplate reader (BioTek Instruments, Inc.). The experiment was performed in triplicate and repeated twice. To determine clonogentic ability, the cells were seeded into a 6-well plate at 1,000 cells/well and cultured for 14 days. Cell colonies were then stained with crystal violet (Beyotime Institute of Biotechnology, Shanghai, China) and counted.

Migration assay. Cell migration assays were performed using Transwell chambers (BD Biosciences, Bedford, MA, USA). Cells $\left(5 \times 10^{5}\right)$ in $200 \mu \mathrm{l}$ serum-free DMEM were seeded in the upper chamber and $800 \mu 1$ medium supplemented with $10 \%$ FBS was added to the lower chamber. The migrated cells were fixed and stained with $0.1 \%$ (w/v) crystal violet $48 \mathrm{~h}$ later. Five randomly selected fields were photographed and the numbers were counted.

Western blot analysis. Cells were lysed in RIPA buffer containing $1 \mathrm{mM}$ PMSF and protease inhibitor cocktail. The protein concentrations were measured by using a BCA Protein Assay kit (Pierce Biotechnology, Inc., Rockford, IL, USA). Then protein samples were separated on $10 \%$ SDS-PAGE gels under reducing condition and transferred onto nitrocellulose membranes (Millipore Corp., Billerica, MA, USA). After blocking in phosphate-buffered saline/Tween-20 (PBST) containing $1 \% \mathrm{BSA}$ at room temperature for $1 \mathrm{~h}$, the membranes were incubated overnight at $4^{\circ} \mathrm{C}$ with the primary antibodies. The following antibodies were used: anti-TR $\beta 1$ (1:500 dilution; Santa Cruz Biotechnology, Inc.), anti-Akt (\#1081-1, 1:1,000 dilution), anti-phospho-Akt (Ser473) (\#2118-1, 1:1,000 dilution) (both from Abcam), and anti- $\beta$-actin (1:10,000 dilution, Sigma-Aldrich). After washing with PBST, the membranes were incubated with species-specific secondary antibodies. Bound secondary antibodies were revealed by Odyssey imaging system (LI-COR Biosciences, Lincoln, NE, USA).

Statistical analysis. Data were analyzed using the Statistical Package for the Social Sciences (SPSS) version 16 (SPSS, Inc. Chicago, IL, USA). The Pearson's Chi-square test was used to analyze the relationship between TR $\beta 1$ expression and clinicophathological characteristics. The two-tailed Student's $\mathrm{t}$-test was used for comparison between two groups. $\mathrm{P}<0.05$ was considered to indicate a statistically significant result.

\section{Results}

TR $\beta 1$ expression is decreased in human CRCs. We firstly analyzed the normalized mRNA expression of TR $\beta 1$ from The 
A

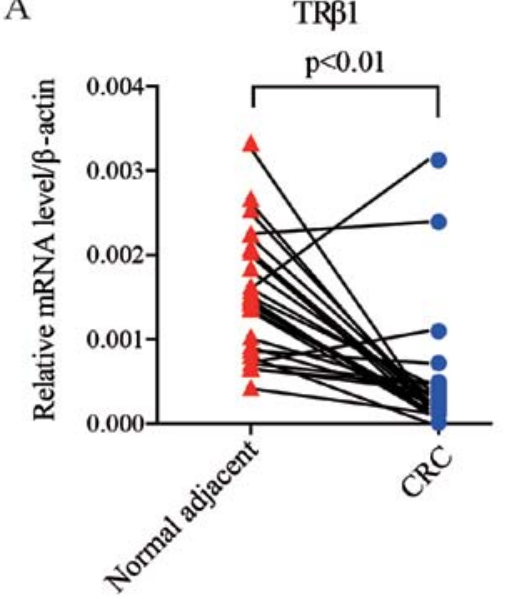

B

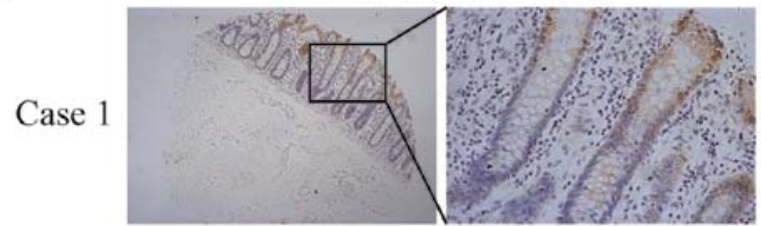

Case 2
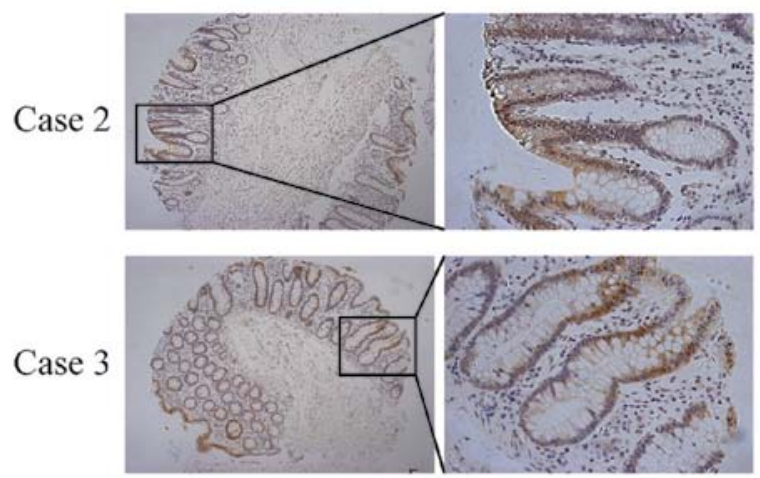

$\times 100$

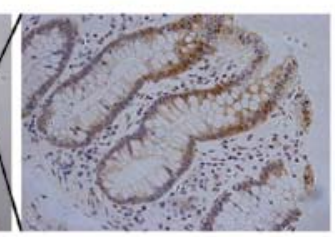

$\times 400$
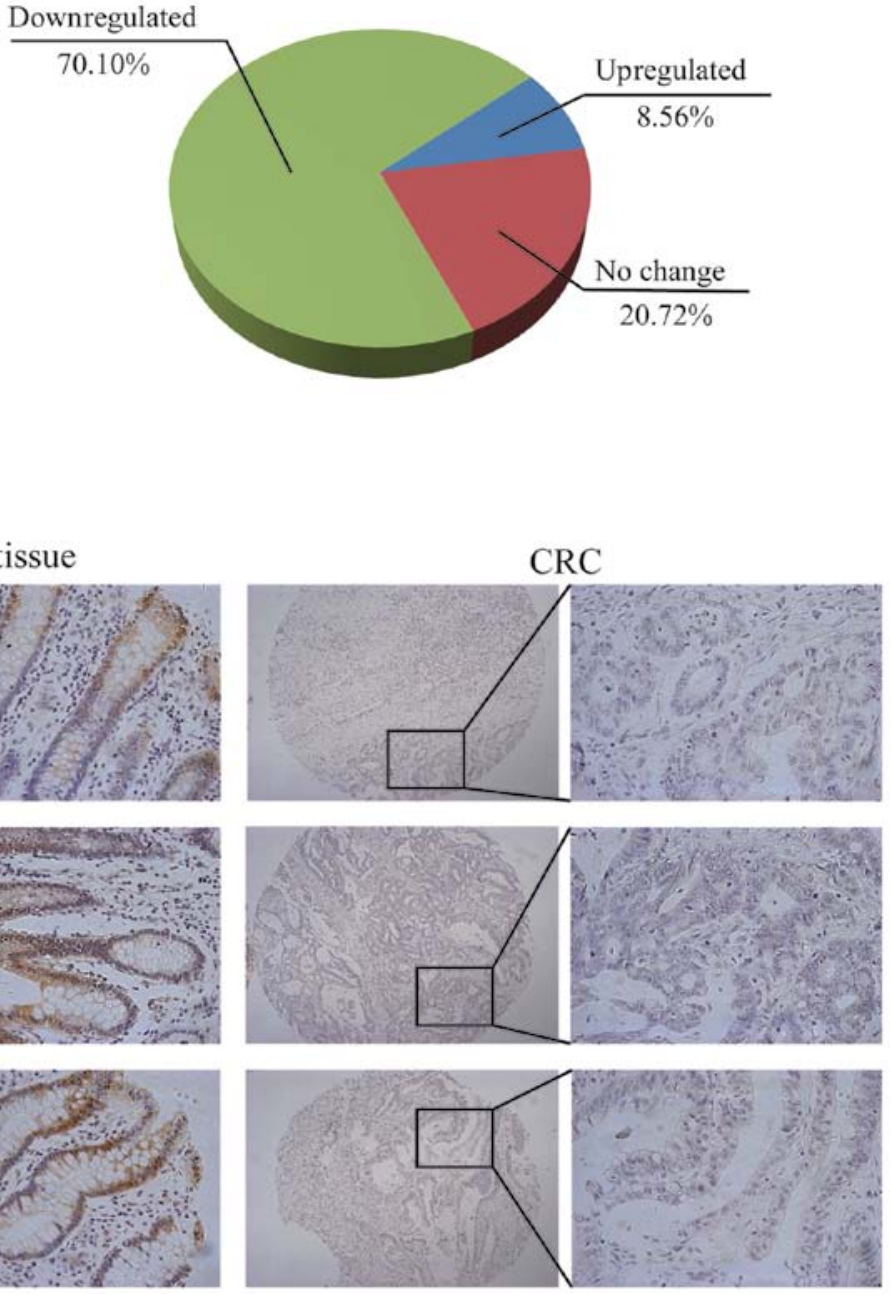

$\times 100$

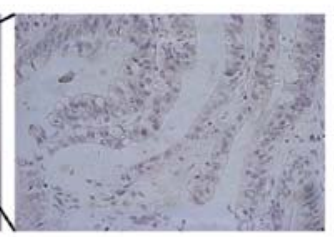

$\times 400$

Figure 2. TR $\beta 1$ expression is downregulated in human CRC tissues. (A) TR $\beta 1$ mRNA expression in 29 pairs of CRC and corresponding adjacent normal mucosal tissues was detected by quantitative RT-PCR. (B) Representative photomicrographs of IHC staining of human CRC tissues and corresponding normal tissues. (C) The expression of TR $\beta 1$ was downregulated in 70.10\% of CRC patients. TR $\beta 1$, thyroid hormone receptor $\beta 1$; CRC, colorectal cancer; IHC, immunohistochemistry.

Cancer Genome Atlas (TCGA) data of 20 cancer types. TR $\beta 1$ expression was decreased in colon adenocarcinoma (COAD) and rectum adenocarcinoma (READ), the data of which were obtained from 41 and 9 pairs of tumor samples and normal tissues, respectively (Fig. 1A). To confirm the TR $\beta 1$ expression level in CRC, we analyzed two independent microarray datasets (GSE20916 and GSE9348) of healthy and CRC patients from the NCBI Gene Expression Omnibus (GEO) dataset-record. The results also showed that TR $\beta 1$ expression was significantly downregulated in the tumor specimens compared with that in the normal colorectal mucosal specimens in these two datasets (fold change was -4.169 and -5.858 respectively, Fig. 1B).

Furthermore, we measured the TR $\beta 1 \mathrm{mRNA}$ and protein levels in CRC tissues. Twenty-nine pairs of CRC and corresponding adjacent normal mucosal tissues were collected and subjected to quantitative real-time PCR. TR $\beta 1$ expression was decreased in $89.7 \%(26 / 29)$ of the CRC patients at the mRNA level, consistent with the data from the TCGA and GEO datasets (Fig. 2A). Using a CRC-TMA containing 222 pairs of CRC specimens and corresponding normal colorectal mucosal tissues, TR $\beta 1$ protein expression was detected by IHC staining. In normal mucosa, TR $\beta 1$ was localized predominantly in the nucleus and cytoplasm of surface epithelium cells, and it was weaker in the crypt bases (Fig. 2B). In carcinomas, TR $\beta 1$ expression was less prevalent (Fig. 2B), and it was downregulated in $70.10 \%$ (157/222) of the CRC patients (Fig. 2C).

These results suggest that attenuated expression of TR $\beta 1$ may contribute to CRC carcinogenesis and progression.

Association between TR $\beta 1$ expression and the clinicopathological features of $C R C$. The basic clinical characteristics of 100 CRC patients are summarized in Table I. The Chi-square test was used to analyze correlations between TR $\beta 1$ protein expression and clinicopathological parameters in the CRC cases. The results indicated that TR $\beta 1$ expression was significantly correlated with tumor size $(\mathrm{p}=0.045)$. No 

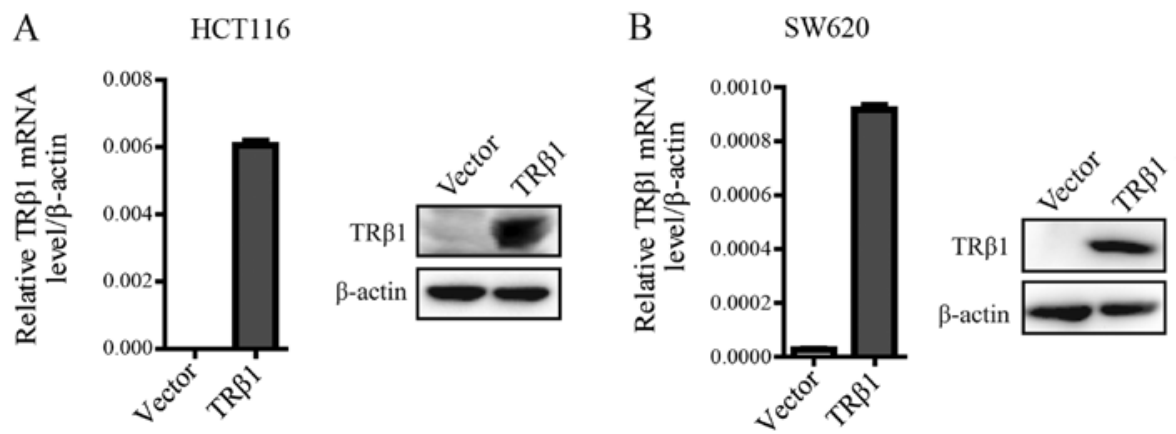

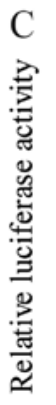

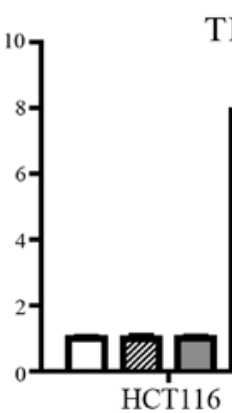

TRE-luc

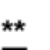

.

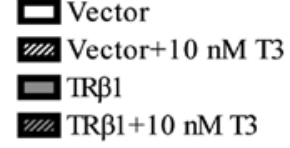

Figure 3. Expression and activity of TR $\beta 1$ were assessed in human CRC cell lines infected with TR $\beta 1$ or lentivirus vector. (A and B) TR $\beta 1$ mRNA and protein expression in HCT116 and SW620 stable cell lines was analyzed by quantitative RT-PCR and western blot analysis. $\beta$-actin was used as internal control. (C) After treatment with $\mathrm{T}_{3}$, ectopic TR $\beta 1$ bound to TRE and triggered luciferase expression. TR $\beta 1$, thyroid hormone receptor $\beta 1$; $C R C$, colorectal cancer; $\mathrm{T}_{3}$, triiodothyroine; TRE, thyroid hormone response element. ${ }^{* *} \mathrm{P}<0.01$, Student's t-test.

Table I. Correlation of TR $\beta 1$ expression with clinicopathological characteristics of the 100 colorectal cancer patients.

\begin{tabular}{|c|c|c|c|c|}
\hline \multirow{2}{*}{$\begin{array}{l}\text { Clinicopathological } \\
\text { features }\end{array}$} & \multirow[b]{2}{*}{ Total } & \multicolumn{2}{|c|}{$\begin{array}{c}\text { Expression } \\
\text { of TR } \beta 1\end{array}$} & \multirow{2}{*}{$\begin{array}{l}\text { P-value } \\
\left(\chi^{2} \text { test }\right)\end{array}$} \\
\hline & & Low & High & \\
\hline \multicolumn{5}{|l|}{ Gender } \\
\hline Male & 56 & 39 & 17 & 0.554 \\
\hline Female & 44 & 33 & 11 & \\
\hline \multicolumn{5}{|l|}{ Age (years) } \\
\hline$\leq 60$ & 28 & 18 & 10 & 0.284 \\
\hline$>60$ & 72 & 54 & 18 & \\
\hline \multicolumn{5}{|l|}{ Tumor size (cm) } \\
\hline$\leq 5$ & 67 & 44 & 33 & 0.045 \\
\hline$>5$ & 33 & 28 & 5 & \\
\hline \multicolumn{5}{|l|}{ Lymphatic metastasis } \\
\hline Yes & 33 & 26 & 7 & 0.289 \\
\hline No & 67 & 46 & 21 & \\
\hline \multicolumn{5}{|l|}{$\begin{array}{l}\text { Histological grade } \\
(\mathrm{WHO})\end{array}$} \\
\hline G1 & 15 & 11 & 4 & 0.907 \\
\hline G2 & 80 & 57 & 23 & \\
\hline G3 & 5 & 4 & 1 & \\
\hline \multicolumn{5}{|l|}{ P53 staining } \\
\hline Yes & 38 & 30 & 8 & 0.226 \\
\hline No & 62 & 42 & 20 & \\
\hline
\end{tabular}

Bold implies statistical significance, $\mathrm{p}<0.05$. TR $\beta 1$, thyroid hormone receptor $\beta 1$. significant difference was found in age, gender, lymphatic metastasis, histological grade and P53 staining between the two groups (Table I).

Overexpression of TR $\beta 1$ inhibits $C R C$ cell proliferation. To identify the function of TR $\beta 1$ in CRC, we established stable cell lines by a lentivirus carrying the TR $\beta 1$ gene in HCT116 and SW620 cells, which exhibit a low endogenous level of TR $\beta 1$. Stable HCT116 and SW620 cells transfected with an empty vector were used as controls. TR $\beta 1$ was overexpressed in the lenti-TR $\beta 1$-infected cells as characterized both by quantitative RT-PCR and western blot analysis (Fig. 3A and B). To ensure that ectopic TR $\beta 1$ was capable to drive gene transcription, we used a luciferase reporter vector containing TRE. The TRE-driven luciferase expression readily responded to $\mathrm{T}_{3}$ in both the HCT116 and SW620 cells stably overexpressing TR $\beta 1$ (Fig. 3C).

CCK- 8 assay was performed to verify the role of TR $\beta 1$ in the two stable CRC cell lines. Compared with the control cells, overexpression of TR $\beta 1$ significantly inhibited the proliferation of the HCT116 and SW620 cells (Fig. 4A). Consistently, TR $\beta 1$ suppressed the colony formation of CRC cells (Fig. 4B).

Overexpression of TR $\beta 1$ suppresses the migration of $C R C$ cells. To further evaluate the effect of TR $\beta 1$ on CRC metastasis, we used Transwell assay. Our findings showed that the number of migrated cells in the TR $\beta 1$-overexpressing group was clearly decreased compared with the number in the control group (Fig. 4C).

Overexpression of TR $\beta 1$ inhibits PI3K/Akt signaling in CRC cells. To elucidate the underlying mechanism of TR $\beta 1$-suppressed CRC cell proliferation and migration, we examined 

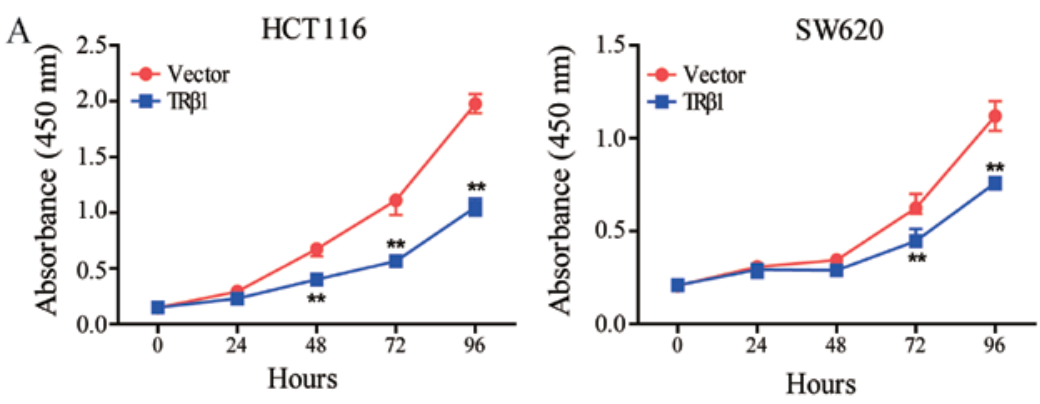

B
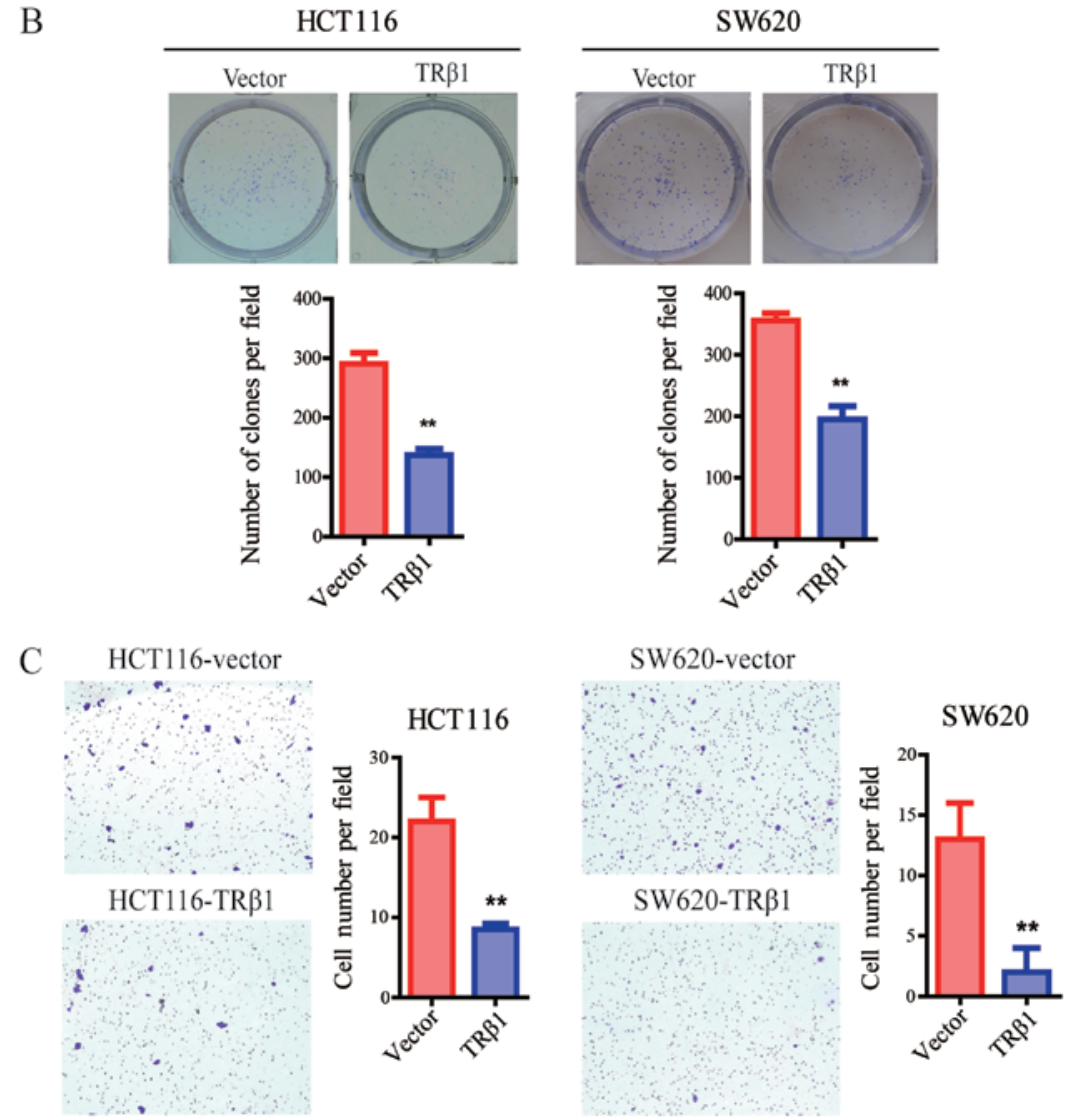

Figure 4. TR $\beta 1$ overexpression inhibits cell proliferation and migration. (A) Cell viability of HCT116 and SW620 cells overexpressing TR $\beta 1$ was determined by CCK-8 assay. (B) Colony formation assay was performed in control and TR $\beta 1$-overexpressing CRC cells. (C) Representative images of migrated cells (left) and statistical analysis of cell migration (right) of HCT116 and SW620 stable cell lines. ${ }^{* *} \mathrm{P}<0.01$, Student's t-test. TR $\beta 1$, thyroid hormone receptor $\beta 1$; CCK-8, Cell Counting Kit-8; CRC, colorectal cancer.

whether PI3K/Akt, which plays an important role in tumor progression (25), was involved in the function of TR $\beta 1$ in CRC cells. As shown in Fig. 5A and B, overexpression of TR $\beta 1$ led to significant decreases in the level of phosphorylated Akt with no change in total Akt expression in both the HCT116 and SW620 cells. When TR $\beta 1$-expressing HCT116 cells were treated with $\mathrm{T}_{3}$, the decrease in pAkt expression was more obvious (Fig. 5C).

Furthermore, the protein expression level of phosphorylated Akt was detected by IHC from the CRC-TMA. We found that phospho-Akt expression was inversely correlated with $\mathrm{TR} \beta 1$ expression in $170 \mathrm{CRC}$ tissues $(\mathrm{R}=-0.166, \mathrm{p}=0.03$, Fig. 5D and E). This result suggests a possible mechanism - TR $\beta 1$ inhibits CRC cell proliferation and migration by suppressing PI3K/Akt signaling.

Taken together, our results demonstrated that overexpression of TR $\beta 1$ suppressed the activation of the PI3K/Akt signaling pathway and inhibited the proliferation and migration of CRC cells (Fig. 5F).

\section{Discussion}

In the present study, we found that TR $\beta 1$ mRNA and protein were downregulated in cancer tissues compared with the levels in their corresponding normal tissues as detected by qRT-PCR and IHC staining, and TR $\beta 1$ expression was significantly correlated with tumor size. In vitro cellular experiments demonstrated that overexpression of TR $\beta 1$ inhibited the proliferation and migration of CRC cells. Moreover, the Akt signaling pathway was suppressed by ectopic TR $\beta 1$ in the CRC tissues and cells. All our data suggest that TR $\beta 1$ acts as a tumor suppressor in CRC progression. For the first time to the best of our knowledge, the functional and clinical significance of TR $\beta 1$ expression was studied in CRC. 

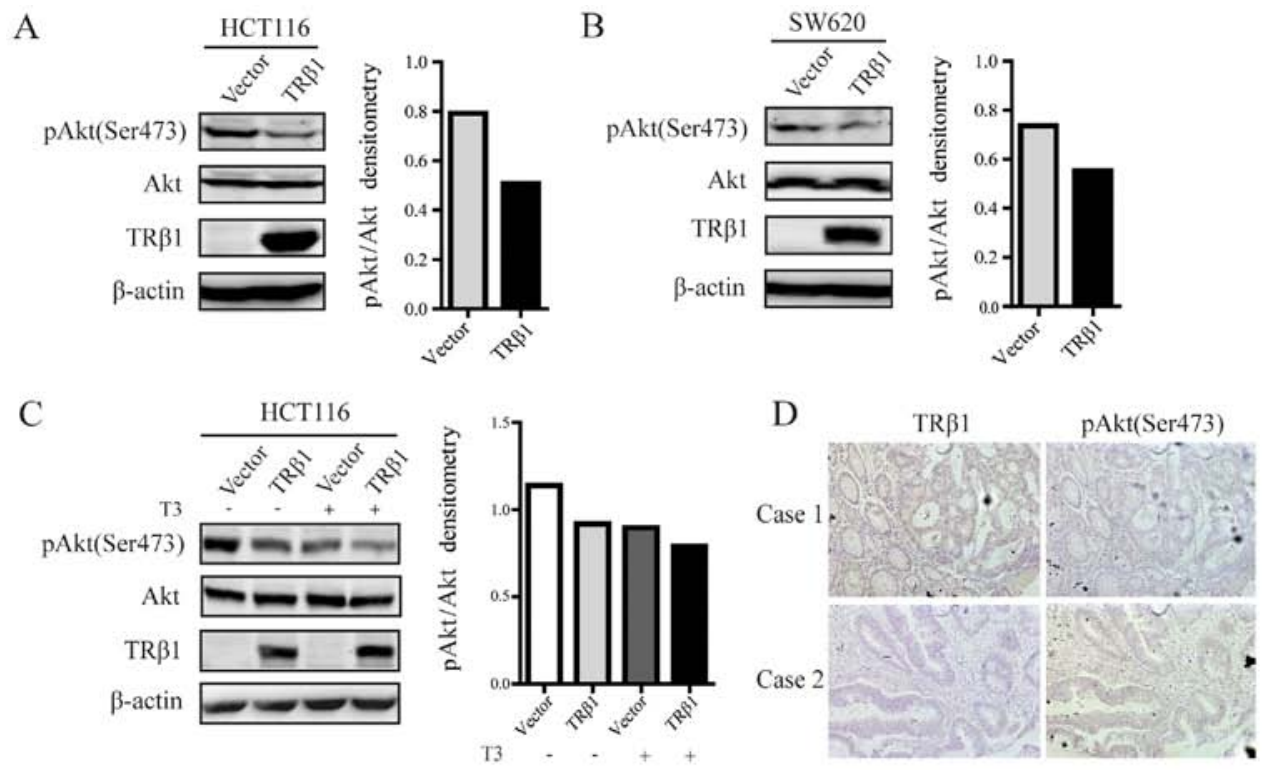

E

\begin{tabular}{|c|c|c|c|c|c|}
\hline & \multicolumn{4}{|c|}{ pAkt(Ser473) } \\
\hline & & - & + & ++ & +++ \\
\hline \multirow{4}{*}{ TR $\beta 1$} & - & 10 & 6 & 3 & 3 \\
\hline & + & 4 & 22 & 11 & 6 \\
\hline & ++ & 30 & 35 & 26 & 0 \\
\hline & +++ & 6 & 8 & 0 & 0 \\
\hline
\end{tabular}

$\mathrm{F}$

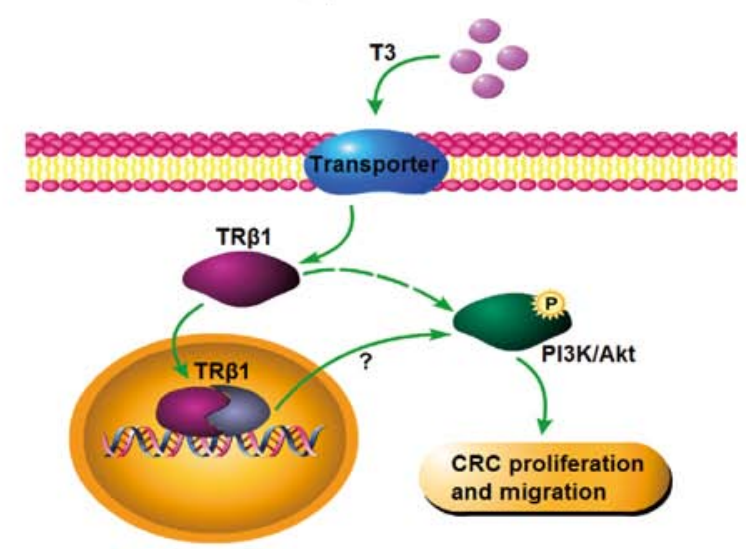

Figure 5. TR $\beta 1$ inhibits activation of the PI3K/Akt pathway. (A and B) Western blot analysis of the expression levels of the indicated proteins in the HCT116 and SW620 cells overexpressing TR $\beta 1$. The images are representative immunoblots. (C) Parental and TR $\beta 1$-expressing HCT116 cells were incubated in serum-free medium alone or in the presence of $10 \mathrm{nmol} / 1 \mathrm{~T}_{3}$ for $24 \mathrm{~h}$. Western blot analysis was performed to detect phosphorylation of Akt. (D) IHC analysis showed a correlation between the expression levels of TR $\beta 1$ and phospho-Akt in consecutive sections of CRC tissues. (E) The number of patients within each phospho-Akt IHC score category relative to TR $\beta 1$ IHC score categorized in whole number increments. The correlation between IHC expression levels of phospho-Akt and TR $\beta 1$ was analyzed by Spearman's rank correlation analysis. (F) A model of the regulation of CRC cell proliferation and migration by TR $\beta 1$ through the PI3K/Akt signaling pathway. TR $\beta 1$, thyroid hormone receptor $\beta 1 ; \mathrm{T}_{3}$, triiodothyroine; IHC, immunohistochemistry; CRC, colorectal cancer.

Aberrant expression or mutations of TRs are common events in human cancer, and TRs also have an important role in tumor progression in cancer cell lines $(20,22)$ and experimental animal models (26-28), suggesting that these receptors may be involved in human cancer. Horkko et al reported that TR $\beta 1$ is always present in normal colorectal mucosal epithelium but less frequent in CRC, and its expression is associated with the presence of K-ras mutations. However, the role of TR $\beta 1$ in the progression of CRC remains unknown. In this study, the TR $\beta 1$ expression pattern was analyzed in datasets (TCGA, GSE20916 and GSE9348) and in human tissues by qRT-PCR and IHC. Consistent with the findings of Horkko et al (30), we confirmed that TR $\beta 1$ expression was decreased in the CRC tissues compared with normal mucosal tissues. Further study revealed that tumor size was closely correlated with TR $\beta 1$ expression. Yet, more clinical samples and data are needed to identify the association between TR $\beta 1$ and overall survival (OS) and disease-free survival (DFS).

Furthermore, the biological functions of TR $\beta 1$ in CRC were detected by cell viability and migration assays. We found that overexpression of TR $\beta 1$ significantly suppressed CRC cell proliferation and migration. Yet, the in vivo role of TR $\beta 1$ in CRC carcinogenesis remains undetermined to date. CRC 
mouse models induced by genetic alterations (e.g., $\mathrm{APC}^{\mathrm{min} /+}$ mice) or by chemical carcinogens are needed to reveal the pathological role of TR $\beta 1$ in colonic carcinogenesis.

The PI3K/Akt signaling pathway modulates the function of numerous substrates involved in the regulation of cell survival, cell cycle progression and cellular growth, and components of this pathway are frequently altered in human cancers. In the present study, we found that overexpression of TR $\beta 1$ resulted in obvious decreased activation of Akt phosphorylation. However, it remains unconfirmed whether the effect of TR $\beta 1$ on cell survival and migration are mediated by the PI3K/Akt pathway. Moreover, TRs physically interact with the regulatory p85 $\alpha$ subunit of PI3K to modulate downstream signaling pathway in thyroid cancer $(21,29)$. Whether or not TR $\beta 1$ inhibits Akt phosphorylation by direct interaction with PI3K in CRC remains unknown. TR $\beta 1$ also acts as a transcriptional factor and may regulate a series of target genes in CRC cells. Which target gene is involved in the suppression of cell viability and migration by TR $\beta 1$, and whether or not these target genes regulate CRC progression via the PI3K/Akt signaling pathway require further investigation.

In summary, this is the first study to report that TR $\beta 1$ plays a critical role in CRC by regulating the PI3K/Akt pathway. Future functional experiments with CRC mouse models are needed to clarify the role of TR $\beta 1$ in CRC progression and metastasis. Although the detailed mechanism remains to be delineated, this preliminary study provides further knowledge of the biological functions of TR $\beta 1$ in CRC and suggests that TR $\beta 1$ could be a potential target for CRC therapeutics.

\section{Acknowledgements}

This study was supported by grants from the National Natural Science Foundation of China (81472678), the Shanghai Natural Science Foundation (13ZR1440100) and the State Key Laboratory of Oncogenes and Related Genes (91-1511). We thank Dr Hao Ying for providing the luciferase reporter vector.

\section{References}

1. Jemal A, Bray F, Center MM, Ferlay J, Ward E and Forman D: Global cancer statistics. CA Cancer J Clin 61: 69-90, 2011.

2. Cunningham D, Humblet Y, Siena S, Khayat D, Bleiberg H, Santoro A, Bets D, Mueser M, Harstrick A, Verslype C, et al: Cetuximab monotherapy and cetuximab plus irinotecan in irinotecan-refractory metastatic colorectal cancer. N Engl J Med 351: 337-345, 2004.

3. Hurwitz H, Fehrenbacher L, Novotny W, Cartwright T, Hainsworth J, Heim W, Berlin J, Baron A, Griffing S, Holmgren $\mathrm{E}$, et al: Bevacizumab plus irinotecan, fluorouracil, and leucovorin for metastatic colorectal cancer. N Engl J Med 350: 2335-2342, 2004.

4. Rovcanin B, Ivanovski I, Djuric O, Nikolic D, Petrovic J and Ivanovski P: Mitotic crossover - an evolutionary rudiment which promotes carcinogenesis of colorectal carcinoma. World J Gastroenterol 20: 12522-12525, 2014.

5. Oppenheimer JH: The molecular basis of thyroid hormone action: Scattered pieces of jigsaw puzzle. Prog Clin Biol Res 74 $45-55,1981$.

6. Mangelsdorf DJ, Thummel C, Beato M, Herrlich P, Schütz G, Umesono K, Blumberg B, Kastner P, Mark M, Chambon P, et al: The nuclear receptor superfamily: The second decade. Cell 83: 835-839, 1995.

7. Muñoz A and Bernal J: Biological activities of thyroid hormone receptors. Eur J Endocrinol 137: 433-445, 1997.
8. Cheng SY: Multiple mechanisms for regulation of the transcriptional activity of thyroid hormone receptors. Rev Endocr Metab Disord 1: 9-18, 2000.

9. Bradley DJ, Towle HC and Young WS III: Spatial and temporal expression of alpha- and beta-thyroid hormone receptor mRNAs, including the beta 2-subtype, in the developing mammalian nervous system. J Neurosci 12: 2288-2302, 1992.

10. Lazar MA: Thyroid hormone receptors: Multiple forms, multiple possibilities. Endocr Rev 14: 184-193, 1993.

11. Tagami T, Nakamura H, Sasaki S, Miyoshi Y and Imura H: Estimation of the protein content of thyroid hormone receptor alpha 1 and beta 1 in rat tissues by western blotting. Endocrinology 132: 275-279, 1993.

12. González-Sancho JM, García V, Bonilla F and Muñoz A: Thyroid hormone receptors/THR genes in human cancer. Cancer Lett 192: 121-132, 2003.

13. Lin KH, Shieh HY, Chen SL and Hsu HC: Expression of mutant thyroid hormone nuclear receptors in human hepatocellular carcinoma cells. Mol Carcinog 26: 53-61, 1999.

14. Puzianowska-Kuznicka M, Nauman A, Madej A, Tanski Z, Cheng $\mathrm{S}$ and Nauman J: Expression of thyroid hormone receptors is disturbed in human renal clear cell carcinoma. Cancer Lett 155: 145-152, 2000.

15. Kamiya Y, Puzianowska-Kuznicka M, McPhie P, Nauman J, Cheng SY and Nauman A: Expression of mutant thyroid hormone nuclear receptors is associated with human renal clear cell carcinoma. Carcinogenesis 23: 25-33, 2002.

16. Silva JM, Domínguez G, González-Sancho JM, García JM, Silva J, García-Andrade C, Navarro A, Muñoz A and Bonilla F: Expression of thyroid hormone receptor/erbA genes is altered in human breast cancer. Oncogene 21: 4307-4316, 2002.

17. Safer JD, Colan SD, Fraser LM and Wondisford FE: A pituitary tumor in a patient with thyroid hormone resistance: A diagnostic dilemma. Thyroid 11: 281-291, 2001

18. Ando S, Sarlis NJ, Oldfield EH and Yen PM: Somatic mutation of TRbeta can cause a defect in negative regulation of TSH in a TSH-secreting pituitary tumor. J Clin Endocrinol Metab 86: 5572-5576, 2001

19. Puzianowska-Kuznicka M, Krystyniak A, Madej A, Cheng SY and Nauman J: Functionally impaired TR mutants are present in thyroid papillary cancer. J Clin Endocrinol Metab 87: 1120-1128, 2002.

20. Martínez-Iglesias O, Garcia-Silva S, Tenbaum SP, Regadera J, Larcher F, Paramio JM, Vennström B and Aranda A: Thyroid hormone receptor betal acts as a potent suppressor of tumor invasiveness and metastasis. Cancer Res 69: 501-509, 2009.

21. Zhu XG,Zhao L, Willingham MC and Cheng SY: Thyroid hormone receptors are tumor suppressors in a mouse model of metastatic follicular thyroid carcinoma. Oncogene 29: 1909-1919, 2010.

22. Chen RN, Huang YH, Yeh CT, Liao CH and Lin KH: Thyroid hormone receptors suppress pituitary tumor transforming gene 1 activity in hepatoma. Cancer Res 68: 1697-1706, 2008.

23. Ringel MD, Hayre N, Saito J, Saunier B, Schuppert F, Burch H, Bernet V, Burman KD, Kohn LD and Saji M: Overexpression and overactivation of Akt in thyroid carcinoma. Cancer Res 61: 6105-6111, 2001.

24. Kim CS, Vasko VV, Kato Y, Kruhlak M, Saji M, Cheng SY and Ringel MD: AKT activation promotes metastasis in a mouse model of follicular thyroid carcinoma. Endocrinology 146: 4456-4463, 2005.

25. Dent P: Crosstalk between ERK, AKT, and cell survival. Cancer Biol Ther 15: 245-246, 2014.

26. Suzuki H, Willingham MC and Cheng SY: Mice with a mutation in the thyroid hormone receptor beta gene spontaneously develop thyroid carcinoma: A mouse model of thyroid carcinogenesis. Thyroid 12: 963-969, 2002.

27. Guigon CJ, Zhao L, Willingham MC and Cheng SY: PTEN deficiency accelerates tumour progression in a mouse model of thyroid cancer. Oncogene 28: 509-517, 2009.

28. Lu C, Willingham MC, Furuya F and Cheng SY: Activation of phosphatidylinositol 3-kinase signaling promotes aberrant pituitary growth in a mouse model of thyroid-stimulating hormone-secreting pituitary tumors. Endocrinology 149: 3339-3345, 2008.

29. Furuya F, Lu C, Guigon CJ and Cheng SY: Nongenomic activation of phosphatidylinositol 3-kinase signaling by thyroid hormone receptors. Steroids 74: 628-634, 2009.

30. Hörkkö TT, Tuppurainen K, George SM, Jernvall P, Karttunen TJ, Mäkinen MJ: Thyroid hormone receptor betal in normal colon and colorectal cancer-association with differentiation, polypoid growth type and K-ras mutations. Int J Cancer 118, 1653-9, 2006. 